\title{
An Updated Primer on SARS-CoV-2 and the Evolving Covid-19 Pandemic
} Dr. Subramani Mani, MBBS, $\mathrm{PhD}^{1}$

\begin{abstract}
In this paper we first provide a primer on SARS-CoV-2 and Covid-19 delineating the etiopathogenesis, epidemiology, clinical manifestations and the natural history of the disease. We then trace the evolution of the Covid-19 pandemic highlighting the characteristics of the epidemic in China where the pandemic originated, select countries of Europe which peaked during April, and Brazil, US and India where the pandemic has taken serious turns recently. We also project some possible trajectories for the mega cities of India based on the demographic characteristics of these cities in comparison to New York city. This is an updated version of the article from mid-April published online [2].
\end{abstract}

Keywords

SARS-CoV-2; Covid-19; pandemic; primer; India; mortality rate; evolution; updated primer; evolving pandemic

\section{Introduction}

Corona virus disease 2019 (Covid-19) caused by severe acute respiratory syndrome corona virus 2 (SARSCoV-2) originated in the city of Wuhan, China in late 2019. After infecting tens of thousands of people in Wuhan and the province of Hubei where Wuhan is located, the disease spread to various other cities of China and internationally. It peaked recently in many countries of Europe (Italy, Spain, France, Germany, United Kingdom) and Asia (Iran, South Korea), is changing course in the United States and currently raging in Brazil, Peru, Russia and India. It has spread to more than 200 countries and is challenging the healthcare resources of both the developed and the developing world. With a global case count in excess of 6 million, and with a mortality of more than 360,000 over a five-month period, the Covid-19 pandemic has become the most dangerous global infectious disease of the $21^{\text {st }}$ century [3].

Humans are susceptible to a range of microbes which include parasites, bacteria and viruses. However, most of the newly identified emerging pathogens are viruses that are carried by vectors, or cause primary disease in animals and then "jump" to humans (zoonotic). These are opportunistic viruses that mutate at high rates, easily adapting to the new human host, thereby enabling human-to-human transmission. The most prominent of these emerging pathogens are the Zika virus and the newer zoonotic respiratory coronaviruses $[4,5]$ which also include the current pandemic-causing virus SARS-CoV-2.

The first SARS-CoV outbreak occurred in late 2002 and soon became a pandemic in early 2003, resulting in the death of more than 700 people with a large cluster of fatalities reported from Hong Kong. This SARS$\mathrm{CoV}$ virus is thought to have originated in a single or multiple species of bats [4]. A more recent coronavirus (CoV) pathogen is the Middle Eastern respiratory syndrome (MERS) CoV, which first emerged in 2012 in Saudi Arabia, and spread to many countries in the region. By 2018 MERS-CoV had infected more than two thousand people, causing 803 deaths, the majority of them in Saudi Arabia. Camels and bats are considered to be reservoirs of this pathogen [6].

\footnotetext{
${ }^{1}$ Formerly associate professor of Medicine and Translational Informatics, University of New Mexico School of Medicine, Albuquerque, NM, USA. Email <subramani.tvm@gmail.com>
} 
Before the emergence of SARS, human coronaviruses typically caused only mild upper respiratory infections, resulting in the common cold. All this changed with the emergence of SARS-CoV, MERS-CoV and the newest member SARS-CoV-2, the causative agent of the Covid-19 pandemic.

\section{Etiology}

Covid-19 is caused by the recently identified respiratory tract virus SARS-CoV-2, which belongs to the viral family coronaviridae, also referred to as the coronavirus family [7]. Other prominent members of the respiratory tract group of viruses are the rhinovirus, the respiratory syncytial virus (RSV) and the influenza and parainfluenza viruses. The coronaviruses are single-stranded RNA viruses, containing an RNA inner

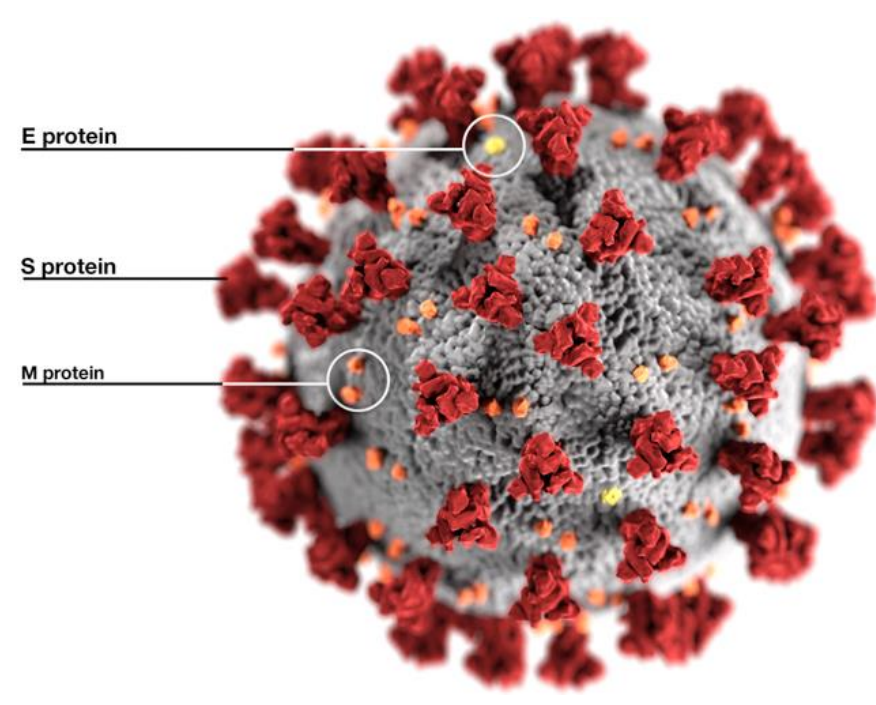

Figure 1: Eckert and Higgins illustration of SARS-CoV-2, Centers for Disease Control and Prevention, USA core with an outer oily lipid envelope from which crown-like spikes of proteins project outwards. These characteristic crown-like projections on their surface give the virions the appearance of a solar corona in electron micrographs and hence the nomenclature "corona". See Figure 1. The corona viruses are heat sensitive and are susceptible to lipid solvents such as acetone, ether, and vinegar (which contains acetic acid). The lipid envelope of the virus also breaks apart on contact with soap.

The viral sequence of SARS-CoV-2 identified by Zhu etal. contains 29,892 nucleotides [7] and the viral genome reported by Wu etal. contains 29903 nucleotides [8]. See Figure 2 for additional genetic details.

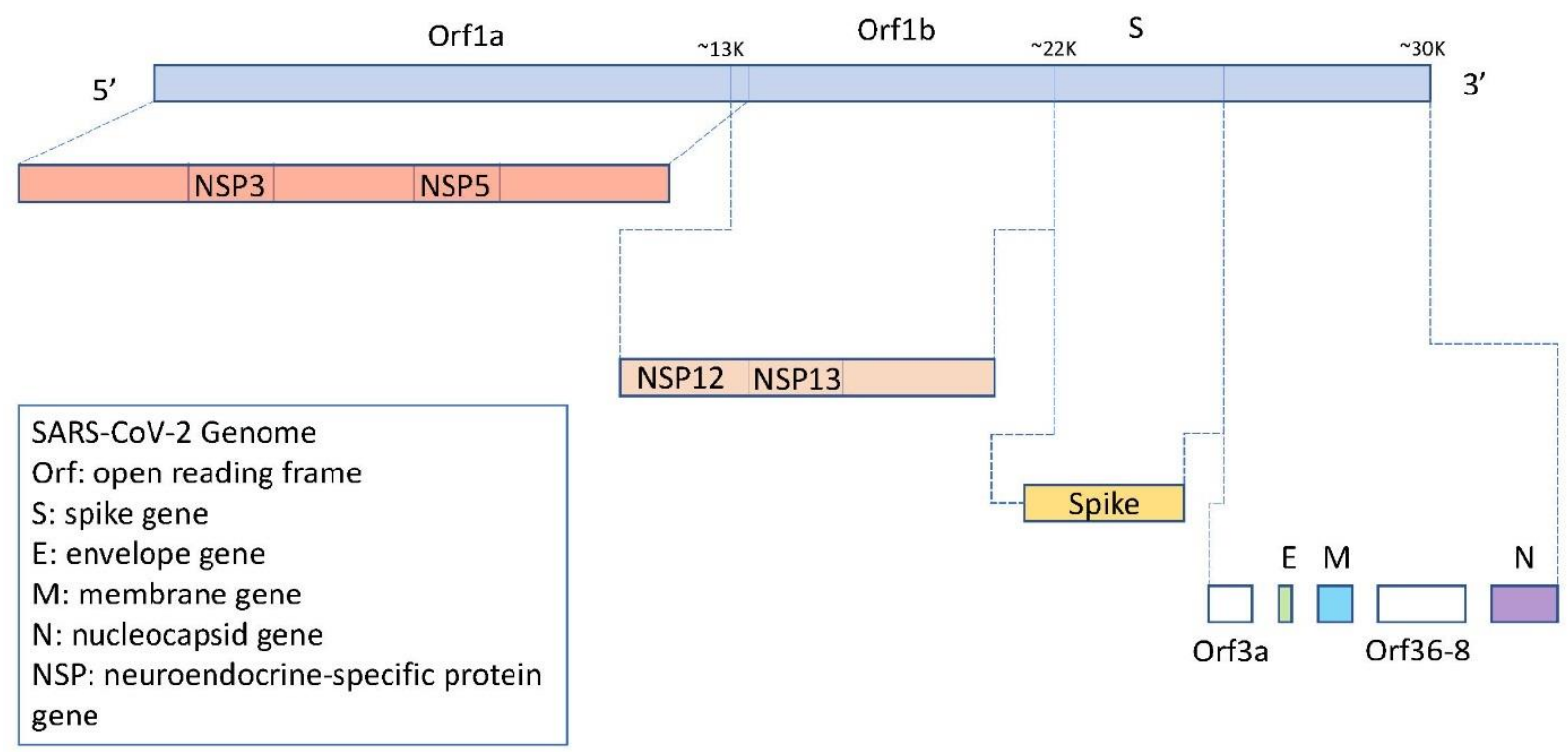

Figure 2: SARS-CoV-2 Genome 


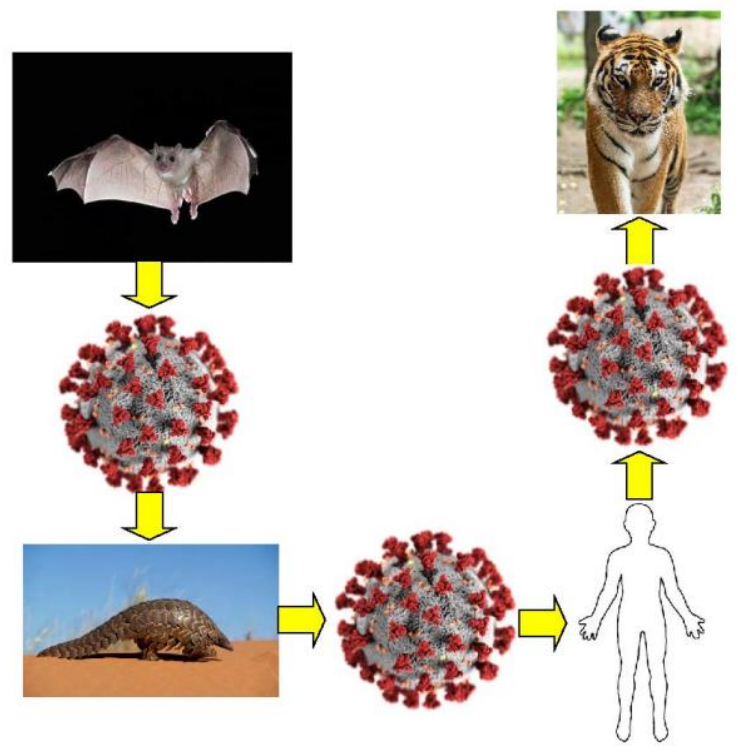

SARS-CoV-2 Transfer

Figure 3: A transmission model from bat to man with pangolin as reservoir.

infected person. Figure 4 provides additional details of the SARS-CoV-2 RT-PCR test.
Phylogenetic analysis revealed the close relationship to SARS-like coronaviruses previously found in bats in China. The pangolin is also likely to be an intermediate host and a natural reservoir of SARS-CoV-2-like coronaviruses [9]. Recently, a jump from human to a tiger in New York city has also been demonstrated when a tiger in the Bronx zoo turned positive. See Figure 3. There are also recent reports of domestic pets such as cats and dogs becoming susceptible to SARSCoV-2 infection [10].

\section{Laboratory diagnosis}

The lab diagnosis of SARS-CoV-2 infection is performed by real-time reverse transcription polymerase chain reaction (RT-PCR) assay for a genetic sequence matching the genome of SARS-CoV-2. This is accomplished by SARS-CoV-2 specific primers and probes. SARS-CoV- 2 is a respiratory virus which is shed in respiratory droplets. A swab taken from the deep nasopharynx is used to isolate the virus from an

Figure 4: SARS-CoV-2 Diagnostic Test Using RT-PCR

\section{Epidemiology}

This description is based predominantly on the following studies---the first 425 confirmed cases in Wuhan, China [11], the second reporting data on 1099 patients admitted to various hospitals in mainland China [12], the third on 138 hospitalized patients in Wuhan [13], the fourth a review article based on 19 studies 
(18 from China and 1 from Australia) which also included the three primary studies [14], the fifth a retrospective cohort study of 191 hospitalized patients in Wuhan with follow-up [15], the sixth a retrospective study of 1591 consecutive patients admitted to ICU in the Lombardy region of Italy [16] and the seventh a study of 5700 hospitalized patients in New York city [17]. Covid-19 is a highly contagious disease, that is, it is easily transmitted from one person to another. The transmissibility factor, also called the basic reproductive number $R_{0}$, is defined as the number of new cases an existing case is likely to generate on average. The $R_{0}$ of Covid-19 is estimated to be 2.2 .

\section{Incubation period}

The incubation period is the duration from the time of exposure to the manifestation of symptoms of the disease. The mean incubation period is 5.5 days with a range of 2 days to 12 days. But there could be outliers and the following table adapted from [18] shows the number of positive cases which could be missed using a 14-day and 28-day protocol of isolation (see Table 1).

Table 1: Expected number of symptomatic SARS-CoV-2 infections missed during active monitoring using 14-day and 28-day protocols with varying risks for infection following exposure (modified from [18])

\begin{tabular}{|l|l|l|l|l|}
\hline \multirow{3}{*}{ Isolation Period } & \multicolumn{4}{|l|}{ Missed Symptomatic Infections per 10,000 Monitored Persons } \\
\cline { 2 - 5 } & $\begin{array}{l}\text { Low Risk } \\
(\mathbf{1 / 1 0 , 0 0 0 )}\end{array}$ & $\begin{array}{l}\text { Medium Risk } \\
\mathbf{( 1 / 1 0 0 0 )}\end{array}$ & $\begin{array}{l}\text { High Risk } \\
\mathbf{( 1 / 1 0 0 )}\end{array}$ & $\begin{array}{l}\text { Infected Sample } \\
\mathbf{( 1 / 1 )}\end{array}$ \\
\hline 14 days & 0 & 0.1 & 1 & 101 \\
\hline 28 days & 0 & 0 & 0 & 1.4 \\
\hline
\end{tabular}

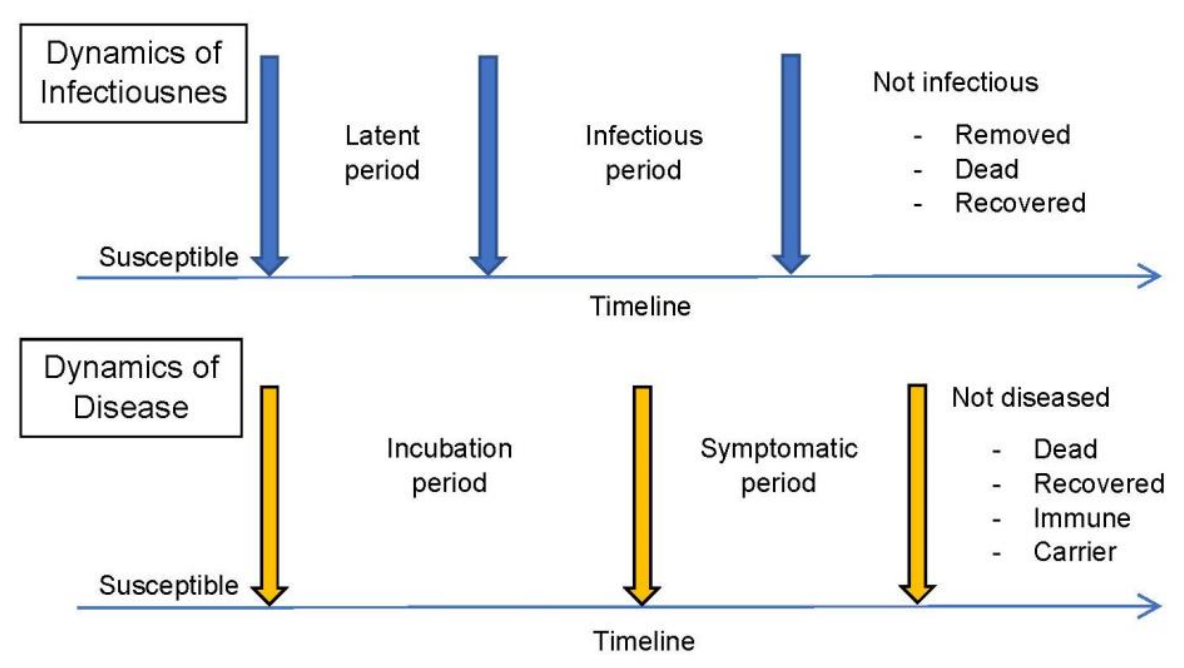

Timelines for infection and disease
The mode of transmission is by respiratory droplets but the virus has also been isolated from the stools of patients. Both symptomatic patients and asymptomatic persons infected with SARS-CoV-2 can transmit the virus [19]. The virus can remain suspended in aerosols for 3 hours raising the possibility of transmission through the air in closed spaces and in a crowded and congested environment. The virus

Figure 3: Dynamics of infection and disease (modified from [1])

can also remain viable for up to 72 hours on different surfaces as varied as plastic, steel, copper and cardboard [20].

Figure 5 provides the dynamics of infectiousness, susceptibility to infection and disease manifestation. The top panel shows how a person could get infected, remain asymptomatic and be contagious. The 
bottom panel shows how a person can be contagious during a part of the incubation period when the symptoms have not manifested.

\section{Demographics}

The median age of patients in different studies varied between 47 and 63 years. Males were disproportionately affected ranging from 50-82 percent. Among the first 425 confirmed cases in Wuhan there were no children below 15 years of age [11]. In the study of 1099 patients, the number of children below 15 years was 9 [12]. Out of the 5700 hospitalized patients in New York City only 26 were children below the age of 10 years [17]. About $15 \%$ of the hospitalized patients were categorized as severe who were on average older by 7 years, and were more likely to have co-existing medical conditions compared to the less severe hospitalized group of patients.

\section{Pathogenesis}

The SARS-CoV2 virus enters the human body via droplets through the nose, mouth or eyes. The virus enters the cells in the airway by binding the viral surface spike protein to the human angiotensin converting enzyme 2 (ACE2) receptor. This follows activation of the spike protein by transmembrane protease serine 2 (TMPRSS2). ACE2 is expressed in the alveolar cells of the lung, heart, vascular endothelium and the kidneys but the main portal of viral entry seems to be the lung alveolar cells [21, 22].

\section{Clinical characteristics}

Fever was present in $40 \%$ of the patients on admission and in $80 \%$ of patients during the hospitalization period. Cough was the second most prevalent symptom and was reported by $70 \%$ of the patients. Half of the patients also reported feeling fatigued. Breathlessness was also observed in $30 \%$ of the patients. Nausea, vomiting, sore throat and headache were uncommon (less than 10\%). A third of the patients had one or more co-existing conditions such as high blood pressure, chronic obstructive pulmonary disease, diabetes, or coronary artery disease and this was more pronounced among patients with severe disease.

\section{Cardiovascular manifestations}

There have been some reports of patients presenting with chest pain and showing ST-segment elevation in the EKG without any evidence of coronary artery disease. In these patients, echocardiography revealed LV dysfunction with reduced ejection fraction and elevated cardiac biomarkers such as troponin. Patients with SARS-CoV-2 infection can also present with myocarditis, stress cardiomyopathy, cardiac failure or they may present with palpitations and chest pain without fever and cough. Patients can also present with shortness of breath, supra-ventricular tachycardia and cardiogenic shock [23]. The exact mechanism of cardiac pathogenesis is not clear [22] but it could be a consequence of systemic hyperinflammation, lymphocytopenia and elevated cardiac stress due to respiratory failure and hypoxemia [24].

\section{Neurological manifestations}

Patients have presented with dizziness, headache, ataxia, altered sensorium and other clinical features suggestive of brain inflammation [25]. A small subset of patients developed stroke and seizures. There are also reports of acute necrotizing encephalopathy in Covid-19 patients. Some patients develop tingling and numbness in the upper and lower limbs referred to as acroparesthesia. Patients have also presented with loss of smell and taste suggesting involvement of the olfactory, facial and glossopharyngeal nerves [26]. In a study of Covid-19 patients in Wuhan, based on a sample of 113 patients who died and 161 patients who recovered, the researchers found that $20 \%$ of deceased patients developed hypoxic encephalopathy while among the recovered group of patients it was observed in only $1 \%$ [27]. 


\section{Cutaneous manifestations}

In a study of 88 patients in the Lombardy region of Italy skin lesions were found in $20 \%$ [28]. The cutaneious manifestations reported are erythematous rash, urticaria, and chickenpox-like vesicles mainly distributed in the trunk. There has also been a report of erythematous chilblain-like lesions on feet and hands in asymptomatic corona virus positive patients [29].

\section{Children and Covid-19}

Compared to adults, children in general have been found to be less susceptible to serious manifestations of Covid-19. Worldwide, patients under eighteen years have so far accounted for only $2 \%$ of severely affected patients even though they can be carriers and transmit the virus [30]. Based on an analysis of 2135 pediatric patients ( 728 lab-confirmed and 1407 suspected) Dong etal. reported that more than $90 \%$ were asymptomatic, mild, or moderate cases. The distribution was similar in both sexes and they found that younger children, particularly infants, were more vulnerable [31]. Researchers have hypothesized that this disparity in the susceptibility to Covid-19 between adults and children could be due to differences in the ACE2 receptors in the renin-angiotensin system (which are used by the SARS-CoV-2 virus to enter the respiratory epithelial cells), and altered inflammatory responses to the pathogen [30, 32].

There have also been recent reports of a multisystem inflammatory syndrome in children due to SARSCoV-2 infection in the UK and US [33, 34].

\section{Radiology and lab features}

Eighty percent of the CT scans of patients with non-severe disease and $96 \%$ of the scans of patients in the severe disease category revealed abnormal findings. The typical patterns on chest CT were ground-glass opacity and bilateral patchy shadowing. These abnormal patterns were also visible in chest X-rays. Less frequent findings found towards the later stages of the disease include septal thickening, bronchiectasis and thickening of the pleura. Other infrequent $\mathrm{CT}$ findings reported with disease progression were pleural effusion, pericardial effusion, lymphadenopathy, lung cavities, CT halo sign and pneumothorax [35].

More than $80 \%$ of patients had a low lymphocyte count. About a third of patients had low white cell counts and another third had low platelet counts. Most patients also showed reduced albumin, high levels of C-reactive protein and elevated ESR. The laboratory findings were more pronounced in patients with severe form of the disease. In a study of 2874 SARS-CoV-2 positive patients RNAemia, that is, detection of viral RNA in blood was found in 97\% [14].

\section{Treatment, clinical course and outcomes}

No specific anti-viral treatment is currently available broadly for Covid-19. A majority of the patients (60\%) were given intravenous antibiotics, and oxygen was administered to about $40 \%$ of the patients. Twenty percent of the patients typically needed admission to the intensive care unit, out of whom half had to be put on ventilators. More than $90 \%$ had pneumonia, $10 \%$ of patients developed acute respiratory distress syndrome and five percent of patients went into shock. The median duration of hospitalization was 12-20 days in different studies with the mortality rate varying from 2 to 20 percent in various studies.

\section{Drug pipeline}

Three drugs that are undergoing studies for effectiveness in the treatment of Covid-19 are Remdesivir, Hydroxychloroquine and Chloroquine. There is some preliminary evidence that these drugs have the potential to inhibit SARS-CoV-2 [36]. Remdesivir is an antiviral compound originally developed as a 
potential drug for Ebola, and Hydroxychloroquine and Chloroquine are time-tested drugs used in the treatment of malaria. Hydroxychloroquine is also indicated in the treatment of discoid, systemic lupus erythematosus and rheumatoid arthritis. A recent placebo-controlled randomized trial of intravenous Remdesivir in hospitalized Covid-19 patients reported a reduction in recovery time by 4 days (from 15 days to 11 days) [37]. An observational study of more than 1300 hospitalized patients did not find any benefit resulting from Hydroxychloroquine administration [38]. A multinational retrospective study of the efficacy of hydroxychloroquine and chloroquine for Covid-19 found higher mortality and increased occurrence of ventricular arrhythmias in both the hydroxychloroquine treated group and chloroquine administered group compared to the control group [39]. Another drug Tocilizumab, an interlukin-6 receptor antagonist used in the treatment of rheumatoid arthritis is also being tested for the treatment of Covid-19 [22].

Recently, a small study involving ten seriously sick Covid-19 patients, who were administered a single dose of $200 \mathrm{ml}$ of convalescent plasma (CP) from recently recovered donors, showed that CP therapy was welltolerated with resulting improvement in clinical symptoms. CP holds promise for improving clinical outcomes by neutralizing the virus circulating in blood [40].

\section{Vaccine trials}

There are various candidate vaccines based on RNA, DNA, recombinant protein, viral-vector-based, as well as the time-tested inactivated, and live attenuated versions under pre-clinical evaluation. Currently, there are no existing licensed human vaccines using RNA and DNA platforms [41]. Two candidate vaccines, one from University of Oxford/AstraZeneca, and another from CanSino Biological Inc./Beijing Institute of Biotechnology, based on non-replicating viral vector platform are currently in phase II trials. Two candidate vaccines based on RNA being developed by Moderna/National Institute of Allergy and Infectious Diseases (NIAID) and BioNTech/Fosun Pharma/Pfizer are also moving into phase II trials. Six other candidate vaccines are also undergoing clinical evaluation.

However, availability of a safe and effective vaccine for SARS-CoV-2 on a mass scale is at least 12-18 months down the road.

\section{Covid-19 pandemic story so far}

Here we present the story of the Covid-19 pandemic from an analytical perspective based on the numbers available from the worldometer website as of May 27, 2020 [3]. In this analysis we include the top fifteen countries based on the reported number of cases, which includes India and the global figures. A total of 6 million cases and more than 360,000 deaths have been reported worldwide. The United States tops the list with a reported total caseload approaching 1.75 million with more than 100,000 deaths. India has reported more than 158,000 cases and 4534 deaths through May $27^{\text {th }}$. Brazil has counted close to 400,000 cases with total deaths approaching 25,000, and Russia is close behind with a caseload exceeding 370,000 but with a much lower reported death toll approaching 4,000. Spain, United Kingdom, Italy, France and Germany together have reported more than 1.1 million cases with a combined death toll exceeding 134,000 . US also leads the countries in the total number of tests with more than 15 million tests followed by Russia with more than 9.4 million tests. But the testing rate (number of tests per million people) is highest in Spain with more than 76,000 people tested per million inhabitants. 


\section{Covid-19 Mortality Rate (\%) as of \\ May 27th, 2020}

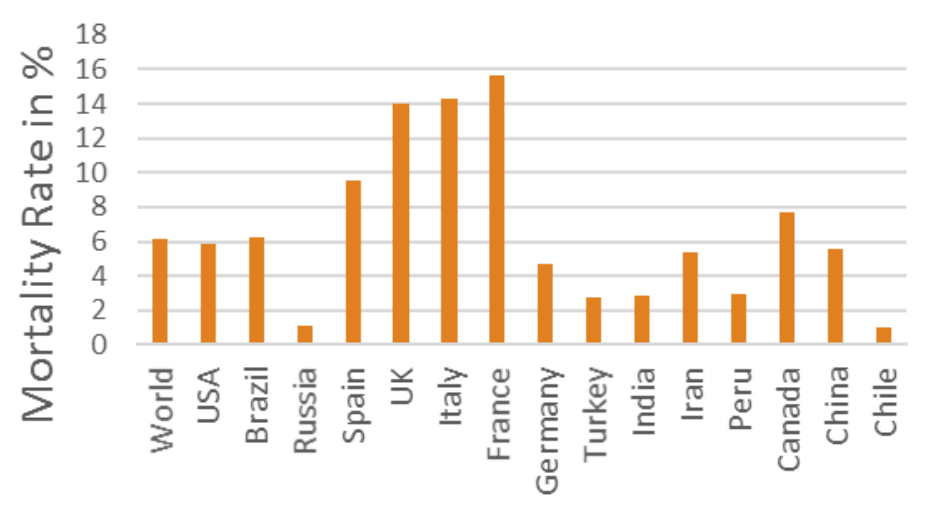

Figure 4: Covid-19 mortality rate
The number of new cases reported daily is an indicator of the evolution of the pandemic on a daily basis in each country. In this measure, US and Brazil top the list with more than twenty thousand new cases in one day. Figure 6 provides the mortality rate of Covid19 for the various countries. The worldwide mortality rate is $6.2 \%$ with a range of $1.0 \%$ for Chile to $>14 \%$ for Italy and the UK. The mortality rate for India stands at $2.9 \%$. For an epidemiological comparison, the fatality rates and reproductive rates of common and emerging virus infections are shown in Table 2.

Table 2: Fatality rate and reproductive rate $\left(R_{0}\right)$ of common and emerging virus infections (modified from [42])

\begin{tabular}{cccc}
\hline Virus & Fatality rate (\%) & Transmissibility Factor $\left.\mathbf{R}_{\mathbf{0}}\right)$ & Deaths \\
\hline SARS-CoV-2 (2019) & 3 & 2.2 & $369,000+$ (till May 30th, 2020) \\
\hline SARS-CoV (2002) & 10 & $2-5$ & 700 \\
\hline MERS-CoV (2012) & 40 & $<1$ & 800 \\
\hline H1N1 (2009) & 0.03 & $1.2-1.6$ & $18,600-300,000$ \\
\hline H1N1 (1918) & 3 & $1.4-3.8$ & $17-50$ million (1918-1920) \\
\hline Measles virus & 0.3 & $12-18$ & 140,000 in 2018 \\
\hline Seasonal flu & $<0.1$ & $1.2-2.4$ & $0.3-0.6$ million per year currently \\
\hline Ebola virus (2014-16) & 40 & $1.5-2.5$ & 11,300 (2014-2016) \\
\hline HIV & 80 (without drug therapy) & $2-4$ & 30 million total deaths so far \\
\hline Small pox virus & 17 & $5-7$ & 300 million in 20 \\
\hline
\end{tabular}

\section{Discussion}

The pandemic continues to spread and evolve on a global scale. It has overwhelmed the healthcare capabilities and capacities of various cities and countries including Wuhan (China), Italy, Spain, France, UK and New York, causing fatalities in the thousands, tens of thousands and even one hundred thousand. As countries attempted (and continuing) to block the spread of Covid-19 by proclamations of stay-in-place and lockdown orders in cities, states and nation-wide, the economies of these countries are taking a huge hit and sliding towards recession.

Recall that the transmissibility of a contagion is defined by the reproductive number $\mathrm{R}_{0}$ in epidemiological terms. There are two basic strategies to tackle the spread of Covid-19 referred to as containment and mitigation. When the $R_{0}$ is two or greater there will be an exponential spread as each case will generate two or more new cases on average and the total number of cases in a community or a geographical region starts doubling every few days. A containment strategy is typically used the beginning of an epidemic and involves testing persons exposed to the virus, isolating and quarantining them individually, and tracing their contacts if they test positive or develop symptoms. In the containment approach the goal is to keep $\mathrm{R}_{0}$ below one to break the community transmission chain. 
To tackle an exponential spread and when the number of cases overwhelms containment approaches, a mitigation approach is taken using various types of non-pharmacological interventions (NPI) with the goal of lowering $R_{0}$ as much as feasible but not to reduce it to one or below one. The common NPIs involve the steps of extensive testing, isolation/quarantine and social distancing measures for certain population groups such as senior citizens and people with pre-existing medical conditions, or the population as a whole with lockdowns and stay-in-place declarations. Mitigation steps also involve the closure of schools and colleges, shutting down places of entertainment such as performance venues, religious congregations and places of worship, and sports events. Likewise, a drastic reduction in gatherings such as marriages and funerals are also enforced. Both these approaches may need to be applied in tandem in large parts of a country or geographical region facing the onslaught of Covid-19.

\section{Covid-19 run in China, South Korea, Europe and US}

\section{China}

The novel corona virus originated in December in the city of Wuhan in China and started spreading in the province of Hubei which includes Wuhan. When cases started multiplying and authorities suspected human to human transmission of the new virus, containment measures were instituted. By the end of December, a viral sequence was completed and a week later the novel corona virus was officially announced as the causative pathogen of the outbreak by China CDC [11]. By $13^{\text {th }}$ January a test kit became available for detecting SARS-CoV-2. Within a period of ten days hundreds of people had tested positive for the virus. Moreover, within that timespan more than two thousand people had started showing symptoms of the new disease and visiting hospitals in Wuhan. Even though the authorities hesitated initially, the city of Wuhan was put under lockdown on January $23^{\text {rd }}$. By that time many other cities in China were also seeded with the virus as more than seven million residents of Wuhan had left the city to celebrate the Chinese New Year. On January $24^{\text {th }}$, fifteen other cities within Hubei province, in which Wuhan is situated, were also put under lockdown and on January $30^{\text {th }}$, WHO declared an international public health emergency [43]. Figure 7 provides a timeline of the Wuhan outbreak.

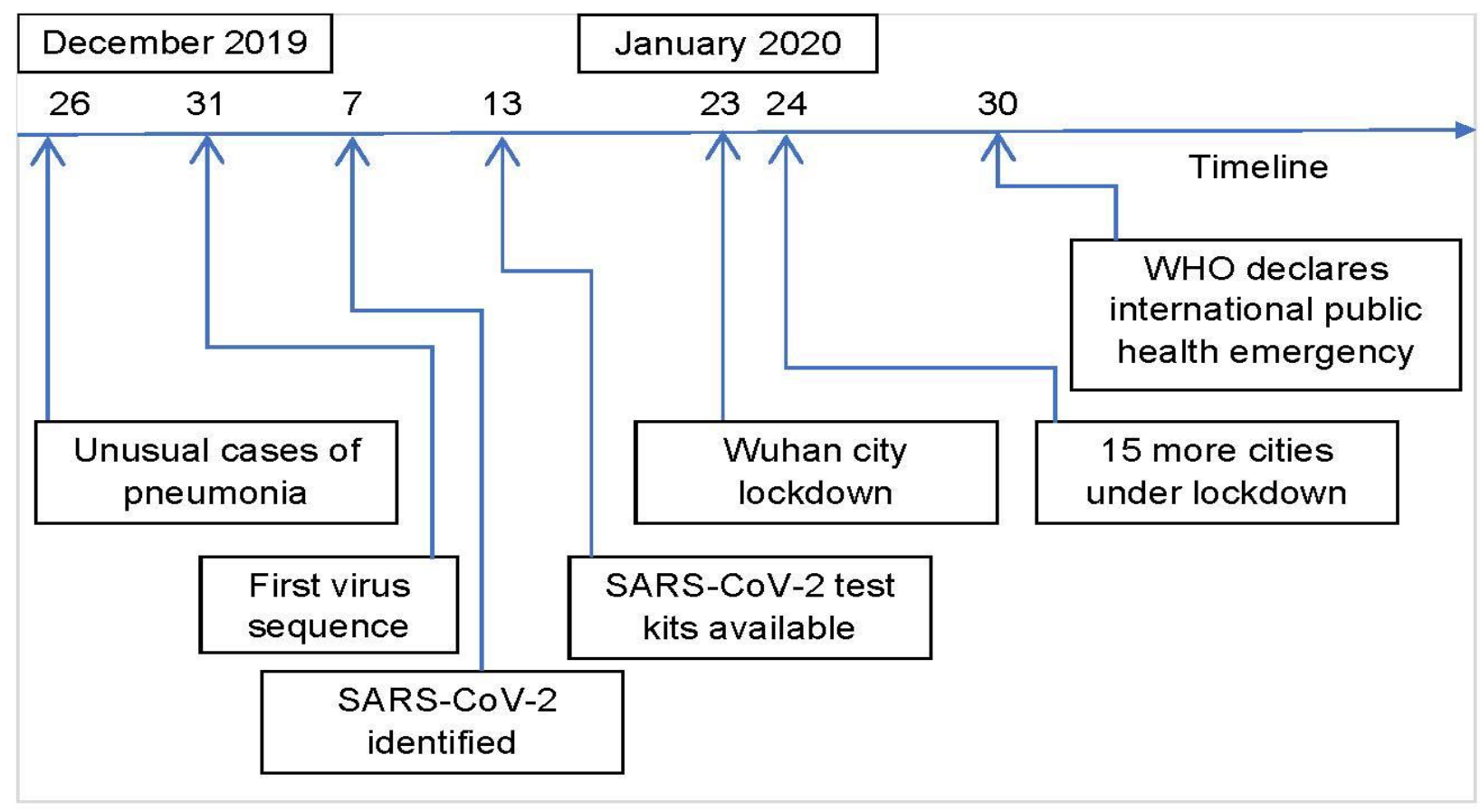

Figure 5: Wuhan Covid-19 outbreak timeline 
China was able to control the smaller outbreaks that occurred outside Hubei province by initiating effective containment measures. However, in the city of Wuhan, and broadly in the Hubei province, the healthcare facilities were overwhelmed by the outbreak. The lockdown in the city of Wuhan was in place for 76 days, and restrictions on the movement of people put in place during the lockdown were slowly relaxed over the last few weeks. At the time of writing (May $27^{\text {th }}$ ), China has reported a total of 83,000 cases and more than 4,600 deaths, mostly in Wuhan and the rest of Hubei province. The country reached the milestone of 80,000 cases in early march which has only increased by 3,000 cases over the last three months.

\section{South Korea}

The first case of Covid-19 was reported on January $20^{\text {th }}$ and by February $21^{\text {st }}$ the caseload increased to 346 , with the outbreak concentrated in the city of Daegu in the southern part of the country [44]. South Korea cancelled mass gatherings in Daegu and effected containment measures incorporating mass testing, contact tracing, isolation of exposed individuals and quarantining those who tested positive. In late February and early March, the country reported more than 500 cases daily and by mid-March, the outbreak was under control reporting less than 250 new cases. And by mid-April, the number of daily new cases had come down to about 25. It fluctuated between single-digit numbers and forty from $1^{\text {st }}$ through the $27^{\text {th }}$ of May. The total number of deaths through May $27^{\text {th }}$ stands at 269 for a total positive case count of 11,344 . South Korea did not institute a countrywide shutdown or social distancing measures applicable to the whole of the country.

\section{Europe}

The Covid-19 pandemic opened its account in Europe with the first reported case in France on January $21^{\text {st }}$ and by May $25^{\text {th }}$, the case count had gone up to more than 1.3 million. As of May $25^{\text {th }}$, the total number of deaths has exceeded 161,000 in the whole of the European Union (EU) including UK [45]. We consider five countries-Italy, Spain, France, Germany and UK in additional detail here.

Italy

Covid-19 first emerged in Italy on January $31^{\text {st }}$ when two tourists from China tested positive. Three weeks later, a cluster of cases was reported from the Lombardy region of Italy which includes Milan, and by early March positive cases were reported from many parts of the country [46]. By March $1^{\text {st }}$, the daily case count had increased to more than 500. The epidemic raged in Italy throughout March and the first two weeks of April with the total case count reaching more than 178,000 with a death toll exceeding 23,600 by April $19^{\text {th }}$. The peak started flattening by mid-April and the daily caseload has started declining from the high three-thousands in mid-April to a few hundred new cases by the last week of May. The total case count tops 231,000 with a cumulative death count exceeding 33,000 as of May 27 2020.

Spain

The country reported its first case on January $31^{\text {st }}$, and by mid-March the disease had spread to all the 50 provinces [47]. By the $10^{\text {th }}$ of March, the daily new case count had increased to more than 500 and the country reached its peak during the last week of March, and the plateau was sustained through the first week of April. As of April 19 ${ }^{\text {th }}$, the total case count had reached close to 200,000 with a total death toll exceeding 20,000. Five weeks later, as of $27^{\text {th }}$ of May, the total case count exceeds 230,000 with a total death toll topping 27,000 . 
France

The epidemic raised its head first in France on January $24^{\text {th }}$, and the first set of cases was in travelers returning from China. The annual assembly of the Christian Open Door Church attended by 2,500 people was a significant watermark in the spread of the virus, and almost half of the congregants contracted the virus [48]. By March $12^{\text {th }}$, the number of daily reported new cases had gone up to more than 500 and the country reached its peak in the first week of April. By April 19 ${ }^{\text {th }}$, the total case count had exceeded 152,500 with a death toll nearing 20,000 . On May $4^{\text {th }}$, retroactive testing of samples in a French hospital demonstrated the presence of Covid-19 as early as December $27^{\text {th }}$, four weeks before the official confirmation of the country's first case. As of $27^{\text {th }}$ May, the country's total case count exceeds 185,000 with a cumulative death toll of 28,600 . From a daily new case-count exceeding $5 \mathrm{~K}$ in early and mid-April the daily case count has come down to a few hundred in the last week of May.

Figure 6: Italy Spain France and United Kingdom Covid-19 outbreak timeline

\section{Germany}

Covid-19 emerged in Germany in late January, with the first case confirmed near Munich on January $27^{\text {th }}$. On March $8^{\text {th }}$, the government recommended cancellation of events with more than one thousand participants and in mid-March, schools and nurseries were closed. Only the state of Bavaria declared a curfew on March $20^{\text {th }}$, but after two days, the Federal Government decided to forbid gatherings of more than two people. Social distancing measures were also introduced but no formal countrywide stay-in orders were issued [49]. At its peak in late March/early April, the daily new case count exceeded 6,000 but by mid-April it had fallen to about 2,000. As of April $19^{\text {th }}$, the total case count exceeded 144,000 with

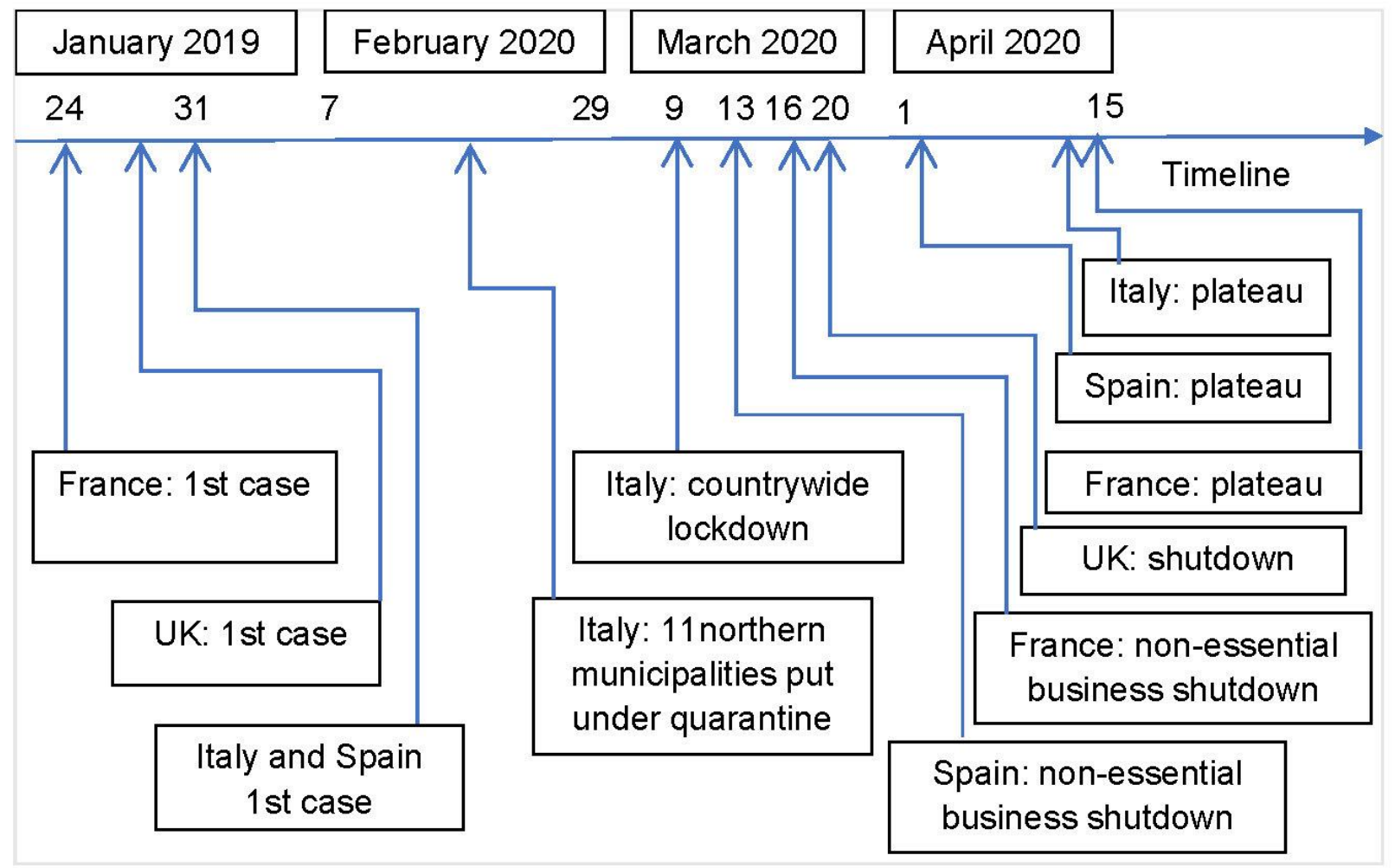

a total fatality count of 4,500 . As of May $27^{\text {th }}$, the total case load is nearing 180,000 with a total death toll exceeding 8,300. From a peak of more than 6,000 daily cases reached late March/early April, the daily case count has come down to a few hundred in the last week of May. 


\section{United Kingdom}

In UK also, Covid-19 was detected first in late January, and by the end of February community transmission within UK was also confirmed [50]. By March $18^{\text {th }}$, the number of daily reported new cases had exceeded 500. As of April $19^{\text {th }}$, the total case count was more than 120,000 with a total death toll over 16,000 . The epidemic has continued to rage in the country through April and May and the total case count exceeds 267,000 as of May $27^{\text {th }}$, with a total death count that tops 37,400 . From a daily new case-count hovering between $4 \mathrm{~K}$ and $6 \mathrm{~K}$ during most of April, and between $3 \mathrm{~K}$ and $5 \mathrm{~K}$ in the first two weeks of May, the daily case load has declined to $2 \mathrm{~K}$ in the last week of May.

See Figure 8 for the evolution of the outbreak through mid-April and the interventions instituted by the respective authorities in Italy, Spain, France and the UK.

\section{United States}

The first Covid-19 case was reported in the US on January $20^{\text {th }}$, when a person who had returned from Wuhan, China, five days earlier tested positive for the virus. Community transmission was first confirmed in late February, when a person without any history of recent international travel or exposure to a known infected individual tested positive [51]. The number of daily new cases exceeded 500 on March $13^{\text {th }}$. Though a travel restriction was instituted on passengers coming from China on January $31^{\text {st }}$, no significant intervention measures were instituted during the whole of February or the first two weeks of March. Containment measures such as extensive testing, isolation and quarantine measures lagged behind considerably in the country. Starting mid-March, when the total case count approached 4,000, various states started instituting mitigation strategies to enforce social distancing measures. Stay at home orders were issued in various states starting with California on March $19^{\text {th }}$, and covered most states of US by April $7^{\text {th }}$.

Starting early May the country started opening up in stages. By May $27^{\text {th }}$, seventeen states have ended stay-at-home orders. Many non-pharmacological interventions such as social distancing measures, restrictions on large gatherings, school closures and wearing of masks in public places are still in place in many regions of the country.

New York has been the most affected state in the United States. The state had a total case count nearing 250,000 and deaths exceeding 18,000 as of April $19^{\text {th }}$. And as of May $27^{\text {th }}$, the total case load is nearing 375,000 with a total death count exceeding 29,500 . The US is also the worst affected country in the world. The country had a total caseload exceeding 750,000 and fatalities exceeding 40,000 as of April $19^{\text {th }}$. This has increased to 1.75 million total cases and a total death count that exceeds 102,000 as of May $27^{\text {th }}$.

\section{Brazil}

The coronavirus was confirmed to have spread to Brazil on February $25^{\text {th }}$ with a Sao Paulo resident who had earlier returned from the Lombardy region of Italy testing positive. It also turned out to be the first positive case in the whole of South America. By March 26 ${ }^{\text {th }}$, the country had 2,915 confirmed cases and 77 deaths. By the end of April, Brazil overtook China in the number of confirmed cases and the country has currently emerged as a hot spot for the virus. Brazil has not instituted countrywide lockdown measures to combat the virus but some cities in the north of the country issued lockdown measures in the first week of May. As of May $27^{\text {th }}$, the total case-load exceeds 411,000 with a cumulative death count in excess of 25,500. Just on May $27^{\text {th }}$ the country added 22,301 new cases and reported 1,148 deaths [52]. 
Russia

The first cases in Russia were reported on January $31^{\text {st }}$, when two Chinese citizens turned positive in the Russian Far East region. Russia was relatively late in experiencing a serious outbreak but currently ranks behind US and Brazil with the third-most number of confirmed cases [53]. As of May $27^{\text {th }}$, the total case load exceeds 370,000 with a total death count approaching 4,000.

\section{India}

Covid-19 raised its head in India in late January with a positive case reported on January $30^{\text {th }}$, in the state of Kerala [54]. By March $24^{\text {th }}$, the total case count had exceeded 500 and the same day the government declared a nationwide lockdown for three weeks, which was further extended on April $14^{\text {th }}$ till May $3^{\text {rd }}$ with a phased relaxation of some restrictions expected to occur after April $20^{\text {th }}$. But the lockdown was further extended by another two weeks through May $17^{\text {th }}$. Based on the success of containment of spread in various states some relaxation was instituted starting in May but the general countrywide lockdown has been extended through the end of the month. By April $19^{\text {th }}$, the total case count exceeded 17,600 with a total death count of 559. As of May $27^{\text {th }}$, the total case load exceeds 158,000 with a total death count in excess of 4,500 . For a country with a population of 1.37 billion, the case count appears low but the country has conducted only about 3 million tests with a testing rate of just 2350 per one million people, while the testing rate for Spain and Russia are about thirty times more with a rate of $76 \mathrm{~K}$ and $64 \mathrm{~K}$ per one million people respectively.

There are some country-specific trends discernible in the evolution of the pandemic till now, in terms of total number of infected people, hospitalizations, the resulting mortality and the ability of the healthcare systems in coping up with the increased demand on their resources. Let us consider the analogy of a primary and its concomitant secondary metastases to follow some of these trends.

China had a clear source, it was unifocal and the outbreak started in Wuhan and more specifically at the Huanan seafood market there. Even though other regions of Hubei province and the rest of the country got multiple-seeded from this outbreak, containment measures were successful in controlling the epidemic outside Hubei province. In Wuhan, and broadly in Hubei, intervention measures began with containment but the hospitals were soon overwhelmed. So, they had to institute strong mitigation efforts in the city of Wuhan and the rest of Hubei province over a period of 75 days to suppress the community transmission. But the primary source was clear to them.

The South Korea outbreak was seeded by travelers from China but it became concentrated in the southern city of Daegu. The country quickly instituted containment measures with extensive testing of the population, contact tracing, isolation and quarantine. The hospitals were never overwhelmed with a total death toll under 300 . Their testing rate stands at 17,000 per million population. The country could prevent a disastrous outbreak in a major population center such as Seoul.

Italy, Spain, France and the UK have some commonalities. They are all well connected globally with extensive travel among them and also with China. It is likely that they were all multiple-seeded and they were slow in scaling up containment measures, starting with extensive testing. These countries were also hesitant in the beginning to initiate strong mitigation efforts. Their health systems, in particular those of Italy, Spain and France were clearly overwhelmed, with a combined death toll which exceeded 65,000 by April $19^{\text {th }}$. The cumulative death count currently stands at 126,000 as of May $27^{\text {th }}$. UK had a long plateau stretching from early April to mid-May putting many of its hospitals under pressure. 
Germany was much better prepared even though it is one of the most well-connected countries. The country quickly instituted strong containment measures with extensive testing in the early stages. Germany was also able to keep the mortality rate very low initially which then crept up somewhat, possibly because hospitalized people started dying after long stays. But the country's healthcare system was not overwhelmed.

US is well connected to China, Europe and most other parts of the world. It is clear from the evolution of the Covid-19 pandemic that the public health infrastructure is lacking in the country. From the start, the country ran into difficulties with its testing strategy. Though initially contact tracing of returning travelers who tested positive was instituted, the machinery for managing and organizing strong containment measures soon broke down, and community transmission started occurring in many population centers in different parts of the country. The tri-state region of New York, New Jersey and Connecticut was severely affected, with hot spots also popping up in Michigan, California and Louisiana. Some hot spots were brought under control by stay-at-home directives, but New York City bore the brunt of the epidemic and many hospitals in the city were overwhelmed exacting a large death toll. Though the first wave of the outbreak is being brought under control, it is not clear how the epidemic will evolve as social distancing measures are relaxed and the businesses open up.

Brazil was in denial about the significance of the pandemic and was late in instituting containment and mitigation measures. Once the country ramped up testing, case counts started to increase and it currently holds the $2^{\text {nd }}$ spot behind US for the total number of positive cases. In particular, the top political leadership of Brazil has opposed many of the restrictive measures announced by city and state leaders.

India is a large populous country with many dense population centers. However, the health infrastructure lacks considerably when compared with most of the countries discussed earlier. For example, South Korea has 12 beds per thousand people and Germany 8 while India has just 0.5. For Italy, China and US, the number is close to 4 .

The first cluster of cases in India was from students traveling back home from Wuhan to the state of Kerala in the southern part of India. Kerala instituted prompt containment measures with isolation of contacts and quarantining people testing positive. Soon other parts of the country also got seeded and dense population centers are now under serious threat. Testing lags considerably with a rate of $2 \mathrm{~K}$ per million population or 2 per one thousand people.

\begin{tabular}{cccccc}
\hline City & $\begin{array}{c}\text { Total Population in } \\
\text { millions }\end{array}$ & $\begin{array}{c}\text { Population Density/Sq. } \\
\text { mile }\end{array}$ & $\begin{array}{c}\text { Beds per 1000 } \\
\text { people }\end{array}$ & $\begin{array}{c}\text { Covid } \\
\text { cases }\end{array}$ & $\begin{array}{c}\text { Total } \\
\text { deaths }\end{array}$ \\
\hline NYC & 8.7 & 28,000 & 3 & 206,000 & 21,000 \\
\hline $\begin{array}{c}\text { Bomba } \\
\text { y }\end{array}$ & 21 & 73,000 & 0.5 & 35,485 & 1,135 \\
\hline Delhi & 30 & 30,000 & 0.5 & 16,281 & 316 \\
\hline $\begin{array}{c}\text { Calcutt } \\
\text { a }\end{array}$ & 15 & 63,000 & 0.5 & 1,895 & 194 \\
\hline $\begin{array}{c}\text { Chenna } \\
\text { i }\end{array}$ & 11 & 69,000 & 0.5 & 12,761 & 109 \\
\hline
\end{tabular}

Table 3: Four mega cities of India compared with New York City (NYC)

Though mitigation efforts in the form of a countrywide lockdown have been instituted relatively early, when compared to many other countries, these cannot be sustained for months in the absence of 
resources to feed and sustain the population. Moreover, the minimal healthcare facilities are likely to be overrun once the lockdown is relaxed. Some relaxation of the lockdown is already happening with a phased opening of businesses and institutions in various states. Domestic flights and long-distance passenger trains have also started to become operational in the last week of May.

Based on the experience of New York City, we provide an outbreak scenario for the four major population centers of India-Bombay, Delhi, Calcutta and Chennai. The projections are based on the total population, population density, the quality of healthcare infrastructure as reflected in the beds per one thousand population and the reported city-specific mortality data. See Table 3 for these parameters and see Figure 9 for the projected cases and fatalities. The lower projections are based on maintaining moderate social distancing measures in place, and the higher range will be reached if mitigation efforts cannot be sustained and compliance is eroded. If mitigation efforts are completely withdrawn, the counts could rise by an order of magnitude.

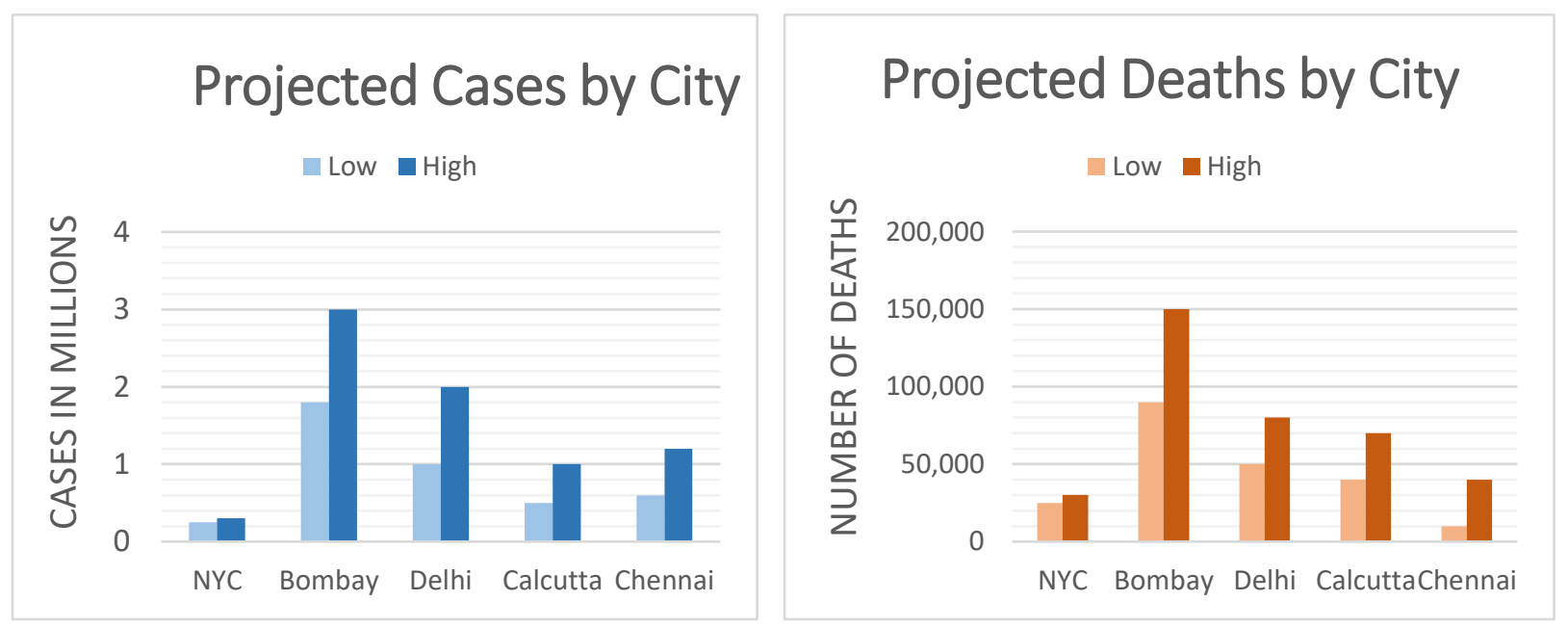

Figure 9: Projected cases and deaths for New York City, Bombay, Delhi, Calcutta and Chennai

The demographics of the state of Kerala provide a set of opportunities, while posing some unique challenges. The state has a total population of 35 million, with an average population density of 2,200 per square mile, which is three times the national average. Again, the coastal regions are more than two times denser than the state average [55]. The coastal plains of Kerala, running north to south from Kasaragod to Trivandrum, act as a metropolitan corridor well-connected by trains and long-distance buses. The region also has three major airports with frequent flights to the countries in the Middle East and the rest of India. Kerala also has a high Human Development Index, which informs favorably on the literacy, life expectancy and the public health infrastructure of the state in general. Kerala has managed to contain the spread of Covid-19 by testing travelers, isolating contacts and quarantining people testing positive. However, testing has lagged behind considerably in assessing penetration in the community to get a clear handle on the prevalence of Covid-19. There are four dense metro areas in the state with a population of 1 to 2 million - Kochi, Trivandrum, Calicut, and Quilon, and only by extensive testing can hot spots be quickly picked up and snuffed out in time to prevent flare ups. Extensive testing is critical when social distancing measures are relaxed.

An outlook similar to India is likely in many of the densely populated countries of Asia (for example, Indonesia, Bangladesh, Pakistan, Japan) and most countries of Africa, South America and also Mexico. One 
worrying common denominator is the number of people tested per million which stands very much under 3 per 1,000 in all these regions.

There is also a line of thinking that opposes social distancing measures by means of shut downs and stayin orders; they oppose closure of educational institutions, businesses and events. They want the younger working populace to acquire herd immunity, and segregate the older people and others who are at risk of developing severe manifestations with poor outcomes. However, it is becoming clearer that many younger people are also getting hospitalized and losing their lives. Moreover, the US alone lost more than 37,000 seniors and staff members to Covid-19 in nursing homes and other long-term care facilities where they are kept typically separate from the younger population.

In a country such as India, with joint-family households where children, parents and grandparents live in the same household, segregating seniors is not a viable proposition. Riding out the pandemic without instituting containment and mitigation measures will overwhelm the healthcare system, resulting in carnage in almost all population centers. For a contagious disease with a high mortality rate, herd immunity has to be acquired with effective vaccines.

\section{Summary and conclusion}

Covid-19 originated in China and within a few weeks, it had infected tens of thousands of people, overwhelmed hospitals, and caused thousands of deaths. It then quickly spread to many other countries in Asia, Europe and the Americas. It has also slowly found its way into many countries of Africa and has truly emerged as a global pandemic. But the magnitude and severity of the spread in different countries varies considerably. Currently Covid-19 is raging in the United States, Brazil, Russia, UK, India and other countries. The virus is like a slow-moving tsunami that has acquired the ability to launch outbreaks at the time and place of its choosing. There are some knowns but many unknowns surrounding the SARS-CoV-2 virus.

An effective vaccine which can confer definitive protection against Covid-19 appears to be at least 18 to 24 months away, though many scientists are in a race to develop such a vaccine and ten candidate vaccines are currently in phase $\mathrm{I} / \mathrm{II}$ trials. Likewise, there is no definitive drug treatment for the condition though a handful of drugs including the anti-viral drug Remdesivir and the anti-malarial drugs Hydroxychloroquine and Chloroquine are being evaluated in clinical studies for their efficacy. Because of the increased mortality and cardiac arrhythmias reported by one large study [39] and lack of clinical benefit observed in another [38], Hydroxychloroquine and Chloroquine are quickly going out of favor.

In the absence of vaccines and definitive drugs, the only effective resistance against the contagion seems to be vigorous containment and mitigation efforts to alleviate the onslaught of Covid-19. Effective public health measures, improved public sanitation and meticulous observation of the best practices of personal hygiene will also help in breaking the chain of community transmission of the contagion. The pandemic has reinforced the age-old but often sidelined aphorism that prevention is better than cure.

After providing a primer on Covid-19, we have charted the early stage of the pandemic which started in China and then moved quickly mainly to the countries of the western world, picking through their health systems and decimating many senior living facilities. The pandemic has also laid bare the disparities and inequities in healthcare access and delivery to different segments of the population in all the affected countries. We have also provided a window to the next stage where the pathogen is spreading its tentacles to the developing countries of Asia, Africa and South America. As the pandemic evolves further, 
the virus is also likely to cycle back during fall into the countries ravaged earlier. Covid-19 is likely to remain endemic and get entrenched in many parts of the world till an effective vaccine emerges to stop the SARSCoV-2 virus in its tracks.

\section{References}

1. Weiss NS: Clinical Epidemiology. In: Modern Epidemiology. Edited by Rothman KJ, Greenland SS. Philadelphia: Lippincott-Raven; 1998.

2. Mani S: A Primer on SARS-CoV-2 and the Covid-19 Pandemic. In., v1 edn; 2020.

3. Worldometers.info: COVID-19 Coronavirus Pandemic. In.; 2020.

4. Froude $\mathrm{S}$, Hughes $\mathrm{H}$ : Newly discovered viruses. In: Oxford textbook of medicine 6th ed. Edited by Firth J, Conlon C, Cox T; 2020.

5. Peiris M: Respiratory tract viruses. In: Oxford textbook of Medicine 6th ed. Edited by Firth J, Conlon C, Cox T: Oxford University Press; 2020.

6. Al Mutair A, Ambani Z: Narrative review of Middle East respiratory syndrome coronavirus (MERS-CoV) infection: updates and implications for practice. Journal of International Medical Research 2020, 48(1):0300060519858030.

7. Zhu N, Zhang D, Wang W, Li X, Yang B, Song J, Zhao X, Huang B, Shi W, Lu R: A novel coronavirus from patients with pneumonia in China, 2019. New England Journal of Medicine 2020.

8. Wu F, Zhao S, Yu B, Chen Y-M, Wang W, Song Z-G, Hu Y, Tao Z-W, Tian J-H, Pei Y-Y: A new coronavirus associated with human respiratory disease in China. Nature 2020, 579(7798):265269.

9. Zhang $T, W u$, Zhang Z: Probable pangolin origin of SARS-CoV-2 associated with the COVID-19 outbreak. Current Biology 2020.

10. Shi J, Wen Z, Zhong G, Yang H, Wang C, Huang B, Liu R, He X, Shuai L, Sun Z: Susceptibility of ferrets, cats, dogs, and other domesticated animals to SARS-coronavirus 2. Science 2020.

11. Li Q, Guan X, Wu P, Wang X, Zhou L, Tong Y, Ren R, Leung KS, Lau EH, Wong JY: Early transmission dynamics in Wuhan, China, of novel coronavirus-infected pneumonia. New England Journal of Medicine 2020.

12. Guan W-j, Ni Z-y, Hu Y, Liang W-h, Ou C-q, He J-x, Liu L, Shan H, Lei C-I, Hui DS: Clinical characteristics of coronavirus disease 2019 in China. New England Journal of Medicine 2020.

13. Wang D, Hu B, Hu C, Zhu F, Liu X, Zhang J, Wang B, Xiang H, Cheng Z, Xiong Y: Clinical characteristics of 138 hospitalized patients with 2019 novel coronavirus-infected pneumonia in Wuhan, China. Jama 2020.

14. Rodriguez-Morales AJ, Cardona-Ospina JA, Gutiérrez-Ocampo E, Villamizar-Peña R, Holguin-Rivera Y, Escalera-Antezana JP, Alvarado-Arnez LE, Bonilla-Aldana DK, Franco-Paredes C, Henao-Martinez AF: Clinical, laboratory and imaging features of COVID-19: A systematic review and metaanalysis. Travel Medicine and Infectious Disease 2020:101623.

15. Zhou F, Yu T, Du R, Fan G, Liu Y, Liu Z, Xiang J, Wang Y, Song B, Gu X: Clinical course and risk factors for mortality of adult inpatients with COVID-19 in Wuhan, China: a retrospective cohort study. The Lancet 2020.

16. Grasselli G, Zangrillo A, Zanella A, Antonelli M, Cabrini L, Castelli A, Cereda D, Coluccello A, Foti G, Fumagalli R: Baseline characteristics and outcomes of 1591 patients infected with SARS-CoV-2 admitted to ICUs of the Lombardy region, Italy. Jama 2020, 323(16):1574-1581.

17. Richardson S, Hirsch JS, Narasimhan M, Crawford JM, McGinn T, Davidson KW, Barnaby DP, Becker LB, Chelico JD, Cohen SL: Presenting characteristics, comorbidities, and outcomes among $\mathbf{5 7 0 0}$ patients hospitalized with COVID-19 in the New York City area. Jama 2020. 
18. Lauer SA, Grantz KH, Bi Q, Jones FK, Zheng Q, Meredith HR, Azman AS, Reich NG, Lessler J: The incubation period of coronavirus disease 2019 (COVID-19) from publicly reported confirmed cases: estimation and application. Annals of internal medicine 2020.

19. Organization WH: Report of the who-china joint mission on coronavirus disease $\mathbf{2 0 1 9}$ (covid-19). In: Available on-line: https://wwwwhoint/docs/default-source/coronaviruse/who-china-jointmission-on-covid-19-final-report pdf. 2020.

20. van Doremalen N, Bushmaker T, Morris DH, Holbrook MG, Gamble A, Williamson BN, Tamin A, Harcourt JL, Thornburg NJ, Gerber SI: Aerosol and surface stability of SARS-CoV-2 as compared with SARS-CoV-1. New England Journal of Medicine 2020.

21. Hoffmann M, Kleine-Weber H, Schroeder S, Krüger N, Herrler T, Erichsen S, Schiergens TS, Herrler G, Wu N-H, Nitsche A: SARS-CoV-2 cell entry depends on ACE2 and TMPRSS2 and is blocked by a clinically proven protease inhibitor. Cell 2020.

22. Clerkin KJ, Fried JA, Raikhelkar J, Sayer G, Griffin JM, Masoumi A, Jain SS, Burkhoff D, Kumaraiah D, Rabbani L: Coronavirus Disease 2019 (COVID-19) and Cardiovascular Disease. Circulation 2020.

23. Fried JA, Ramasubbu K, Bhatt R, Topkara VK, Clerkin KJ, Horn E, Rabbani L, Brodie D, Jain SS, Kirtane A: The variety of cardiovascular presentations of COVID-19. Circulation 2020.

24. Akhmerov A, Marbán E: COVID-19 and the Heart. Circulation research 2020, 126(10):1443-1455.

25. Mao L, Wang M, Chen S, He Q, Chang J, Hong C, Zhou Y, Wang D, Miao X, Hu Y: Neurological Manifestations of Hospitalized Patients with COVID-19 in Wuhan, China: a retrospective case series study. 2020.

26. Wu Y, Xu X, Chen Z, Duan J, Hashimoto K, Yang L, Liu C, Yang C: Nervous system involvement after infection with COVID-19 and other coronaviruses. Brain, Behavior, and Immunity 2020.

27. Chen T, Wu D, Chen H, Yan W, Yang D, Chen G, Ma K, Xu D, Yu H, Wang H: Clinical characteristics of 113 deceased patients with coronavirus disease 2019: retrospective study. BMJ 2020, 368.

28. Recalcati S: Cutaneous manifestations in COVID-19: a first perspective. Journal of the European Academy of Dermatology and Venereology 2020.

29. Landa N, Mendieta-Eckert M, Fonda-Pascual P, Aguirre T: Chilblain-like lesions on feet and hands during the COVID-19 Pandemic. International Journal of Dermatology.

30. Molloy EJ, Bearer CF: COVID-19 in children and altered inflammatory responses. In.: Nature Publishing Group; 2020.

31. Dong Y, Mo X, Hu Y, Qi X, Jiang F, Jiang Z, Tong S: Epidemiology of COVID-19 among children in China. Pediatrics 2020.

32. Zhu L, Lu X, Chen L: Possible causes for decreased susceptibility of children to coronavirus. In.: Nature Publishing Group; 2020.

33. Mahase E: Covid-19: concerns grow over inflammatory syndrome emerging in children. In.: British Medical Journal Publishing Group; 2020.

34. Riphagen S, Gomez X, Gonzalez-Martinez C, Wilkinson N, Theocharis P: Hyperinflammatory shock in children during COVID-19 pandemic. The Lancet 2020.

35. Salehi S, Abedi A, Balakrishnan S, Gholamrezanezhad A: Coronavirus disease 2019 (COVID-19): a systematic review of imaging findings in 919 patients. American Journal of Roentgenology 2020:1-7.

36. Wang M, Cao R, Zhang L, Yang X, Liu J, Xu M, Shi Z, Hu Z, Zhong W, Xiao G: Remdesivir and chloroquine effectively inhibit the recently emerged novel coronavirus (2019-nCoV) in vitro. Cell research 2020, 30(3):269-271.

37. Beigel JH, Tomashek KM, Dodd LE, Mehta AK, Zingman BS, Kalil AC, Hohmann E, Chu HY, Luetkemeyer A, Kline S: Remdesivir for the Treatment of Covid-19-Preliminary Report. New England Journal of Medicine 2020. 
38. Geleris J, Sun Y, Platt J, Zucker J, Baldwin M, Hripcsak G, Labella A, Manson D, Kubin C, Barr RG: Observational study of hydroxychloroquine in hospitalized patients with Covid-19. New England Journal of Medicine 2020.

39. Mehra MR, Desai SS, Ruschitzka F, Patel AN: Hydroxychloroquine or chloroquine with or without a macrolide for treatment of COVID-19: a multinational registry analysis. The Lancet 2020.

40. Duan K, Liu B, Li C, Zhang H, Yu T, Qu J, Zhou M, Chen L, Meng S, Hu Y: Effectiveness of convalescent plasma therapy in severe COVID-19 patients. Proceedings of the National Academy of Sciences 2020, 117(17):9490-9496.

41. Amanat F, Krammer F: SARS-CoV-2 vaccines: status report. Immunity 2020.

42. Chen J: Pathogenicity and transmissibility of 2019-nCoV-a quick overview and comparison with other emerging viruses. Microbes and infection 2020.

43. Wu Z, McGoogan JM: Characteristics of and important lessons from the coronavirus disease 2019 (COVID-19) outbreak in China: summary of a report of 72314 cases from the Chinese Center for Disease Control and Prevention. Jama 2020.

44. Wikipedia: 2020 coronavirus pandemic in South Korea. In.; 2020.

45. Wikipedia: 2020 coronavirus pandemic in the European Union. In.; 2020.

46. Wikipedia: $\mathbf{2 0 2 0}$ coronavirus pandemic in Italy. In.; 2020.

47. Wikipedia: $\mathbf{2 0 2 0}$ coronavirus pandemic in Spain. In.; 2020.

48. Wikipedia: 2020 coronavirus pandemic in France. In.; 2020.

49. Wikipedia: $\mathbf{2 0 2 0}$ coronavirus pandemic in Germany. In.; 2020.

50. Wikipedia: $\mathbf{2 0 2 0}$ coronavirus pandemic in the United Kingdom. In.; 2020.

51. Wikipedia: $\mathbf{2 0 2 0}$ coronavirus pandemic in the United States. In.; 2020.

52. Wikipedia: $\mathbf{2 0 2 0}$ coronavirus pandemic in Brazil. In.; 2020.

53. Wikipedia: $\mathbf{2 0 2 0}$ coronavirus pandemic in Russia. In.; 2020.

54. Wikipedia: 2020 coronavirus pandemic in India. In.; 2020.

55. worldpopulationreview.com: Kerala Population 2020. In.; 2020. 